\title{
Air embolism and blunt chest trauma
}

\author{
Kenneth M. LeDez, FRCPC
}

Received: 28 July 2011/Accepted: 24 August 2011/Published online: 8 November 2011

(C) Canadian Anesthesiologists' Society 2011

\section{To the Editor,}

I read with interest the case reported in the Journal describing the events surrounding the death of a child from unilateral blunt chest trauma due to coronary and cerebral arterial gas embolism (AGE). ${ }^{1}$ The authors used high frequency oscillatory ventilation (HFOV) for oxygenation with a mean airway pressure of $18 \mathrm{cmH}_{2} \mathrm{O}$ because the child's hemoptysis raised concerns regarding airway-vascular connections. Any form of positive pressure ventilation, including HFOV, may contribute to air embolism when pulmonary vessels are damaged. The authors mentioned methods to ensure "separation of the lungs and the air from the blood", 2,3 and this could have been achieved using a double-lumen endotracheal tube or bronchial blocker (DLT/BB). This and other reported cases ${ }^{4}$ suggest strongly that isolation of a lung or lobe is essential if positive pressure ventilation is used in such circumstances.

Prompt hyperbaric oxygen treatment (HBOT) is indicated for AGE and may be undertaken with a DLT/BB, but HFOV would be difficult and potentially dangerous in a hyperbaric chamber. At six atmospheres absolute (ATA) pressure, bubble volume decreases immediately to $17 \%{ }^{5}$ (Boyles Law) with potential for rapid clinical improvement.

Despite HFOV with $100 \%$ oxygen, sufficient nitrogen likely remained in the patient's lungs to constitute a substantial portion of the embolizing gas. Oxygen solubility, hemoglobin-binding, and metabolism would result in diffusion out of bubbles, but insoluble inert nitrogen gas may

K. M. LeDez, FRCPC ( $₫)$

Memorial University, Health Sciences Centre,

St. John's, NL, Canada

e-mail: kledez@mun.ca persist for days. Hyperbaric oxygen treatment (using U.S. Navy Decompression Table 6A, perhaps with 50:50 oxyhelium while at six atmospheres absolute [ATA]) to reduce cerebral (seizures) and pulmonary oxygen toxicity while eliminating nitrogen from the inspired gas increases the diffusion gradient for enhanced nitrogen elimination and may help to deliver oxygen to ischemic tissues. ${ }^{5}$ Additional benefits may result from HBOT effects on the response to endothelial and systemic inflammatory reactions to the gastissue interface. ${ }^{5}$ At three ATA oxygen (three ATA on $100 \%$ oxygen or six ATA on $50 \%$ oxygen), arterial $\mathrm{pO}_{2}$ may exceed 2,000 $\mathrm{mmHg}$ with normal lungs. Therefore, even with a $50 \%$ shunt and one-lung ventilation, oxygenation inside the chamber is most unlikely to be inadequate. Low pressure continuous positive airway pressure (5 $\mathrm{cmH}_{2} \mathrm{O}$ ) to the unventilated lung could be implemented easily if oxygenation were inadequate; even so, it could have a small risk. However, unless vascular entry of inert gas is stopped using DLT/BB, treatment cannot succeed. This profoundly difficult tragic case suggests low airway pressure HFOV is contraindicated when air is entering the pulmonary vessels, and future optimal management for such cases is DLT/BB and prompt HBOT.

Disclosure There are no disclosures to be made for this publication.

Funding No source of funding was used.

Competing interests None declared.

\section{References}

1. Brederlau J, Muellenbach RM, Wunder C, et al. Delayed systemic air embolism in a child with severe blunt chest trauma treated with high-frequency oscillatory ventilation. Can J Anesth 2011; 58: 555-9. 
2. Dopfmer UR, Braun JP, Grosse J, Hotz, H, Duveneck K, Schneider $M B$. Treatment of severe pulmonary hemorrhage after cardiopulmonary bypass by selective, temporary balloon occlusion. Anesth Analg 2004; 99: 1280-2.

3. Stratmann $G$, Benumof $J L$. Endobronchial hemorrhage due to pulmonary circulation tear: separating the lungs and the air from the blood. Anesth Analg 2004; 99: 1276-9.

4. Ho AM, Lee S, Tay BA, Chung DC. Lung isolation for the prevention of air embolism in penetrating lung trauma. A case report. Can J Anesth 2000; 47: 1256-8.

5. Moon RE, Gorman DF. Treatment of the decompression disorders. In: Brubakk AO, Neuman TS (Eds). Bennett and Elliot's Physiology and Medicine of Diving, $5^{\text {th }}$ Edition. Edinburgh: WB Saunders; 2003 (10.7): 600-50.

\section{Reply}

We very much appreciate Dr. LeDez's comments postulating immediate hyperbaric oxygen treatment (HBOT) and one-lung ventilation as the treatment of choice in this case involving a traumatic alveolar to pulmonary venous fistula. ${ }^{1}$

Undoubtedly, hyperbaric oxygen treatment is indicated for cerebral arterial gas embolism (CAGE), e.g., after a diving accident. However, the availability of such devices is in short supply, even in an industrialized country like Germany. The nearest available HBOT centre is $150 \mathrm{~km}$ from our university clinic.

We are convinced that the recommended strategy, i.e., treating severely injured victims suffering from blunt chest trauma with a double-lumen tube and prompt HBOT, might work only in theory.

Besides the reduced availability of HBOT devices, the HBOT itself might implicate some severe events. It has been shown recently that pulmonary structure pathologies, such as bullous changes, are responsible for cerebral arterial gas embolism during decompression from HBOT. ${ }^{2}$ Therefore, there remains the paradox that on the one hand, decompression from HBOT might be the cause of CAGE over the injured lung, and on the other hand, HBOT is the treatment of choice for CAGE.

On admission in the multislice whole body computed tomography study, the patient exhibited an occipital fracture of the skull. As shown previously, there remains the danger of the development of a tension pneumocephalus after HBOT even in acutely injured patients. ${ }^{3}$

Taken together, HBOT is a treatment option in patients with CAGE. However, in acutely injured patients with blunt chest trauma and the probability of an alveolar capillary fistula, we insist that the best realistic treatment of choice would be the immediate implementation of an extracorporeal lung assist device.

Competing interests None declared

\section{References}

1. Brederlau J, Muellenbach RM, Wunder C, et al. Delayed systemic air embolism in a child with severe blunt chest trauma treated with high-frequency oscillatory ventilation. Can J Anesth 2011; 58: 555-9.

2. Rivalland G, Mitchell SJ, van Schalkwyk J. Pulmonary barotrauma and cerebral arterial gas embolism during hyperbaric oxygen therapy. Aviat Space Environ Med 2010; 81: 888-90.

3. Lee CH, Chen WC, Wu CI, Hsia TC. Tension pneumocephalus: a rare complication after hyperbaric oxygen therapy. Am J Emerg Med 2009; 27: 257.e1-3.

Jörg Brederlau, MD

Helios Klinikum Berlin-Buch, Berlin, Germany

Ralf M. Muellenbach, MD

Markus Kredel, MD

Christian Wunder, MD

Würzburg University Hospital, Würzburg, Germany 